\title{
The Plasma is a Suitable Sample for Moderate Magnesium Deficiency Assessment but the Poor Accuracy of Colorimetric Technique Limits its Use
}

\author{
Soledad Vera, Luz Maria Pozo, René Lopez, Joaquin Diaz and Paulette Conget
}

Facultad de Medicina Clínica Alemana - Universidad del Desarrollo, Centro de Medicina Regenerativa, Chile

Corresponding author: Soledad Vera, Facultad de Medicina Clínica Alemana - Universidad del Desarrollo

Centro de Medicina Regenerativa, Chile, Tel: +56223279498; E-mail: svera@udd.cl

Received: 11 April 2016; Accepted: 20 May 2016; Published: 23 May 2016

Citation: Vera S, Maria Pozo L, Lopez R, et al. The Plasma is a Suitable Sample for Moderate Magnesium Deficiency Assessment but the Poor Accuracy of Colorimetric Technique Limits its Use. Ann Clin Lab Res. 2016, 4:2.

\section{Abstract}

Background: The broadly disseminated notion that plasmatic concentration of magnesium is not a good indicator of its corporal status bases on the fact that normal magnesemia is reported in people with magnesium deficiency. The aim of this study was to identify a suitable sample for the assessment of magnesium corporal status in magnesium moderate deficiency.

Methods and Findings: Female mice were fed with regular or low magnesium diet for $\mathbf{4 5}$ days. Bone, muscle, platelets and plasma were sampled and magnesium content was determined by atomic absorption spectrophotometry or using a colorimetric assay. As expected, magnesium content in bones was significantly diminished in animals fed with low magnesium diet when compared with those fed with normal diet (14.6 \pm 0.5 versus $16.7 \pm 0.2 \mathrm{mmol} / 100 \mathrm{~g}, \mathrm{p}<0.05)$. Magnesium moderate deficiency was replicated in plasma ( $0.76 \pm 0.08$ versus $0.94 \pm 0.09 \mathrm{mmol} / \mathrm{L}, \mathrm{p}<0.05$ ) but not in muscle or platelet samples. The correlation between bone and plasma magnesium contents was 0.53 . ROC curve analysis revealed $83 \%$ specificity and $75 \%$ sensitivity for plasma magnesium cut off of $0.84 \mathrm{mmol} / \mathrm{L}$.

Conclusion: Plasma is a suitable sample to determine magnesium corporal status when deficiency is moderate. But, poor accuracy of colorimetric technique limits its use.

Keywords: Magnesium, Corporal status, Deficiency, Assessment, Plasma

\section{Introduction}

Magnesium is an intracellular divalent cation involved in many cellular processes, among others energy metabolism, DNA transcription and protein synthesis [1]. Due to food processing and impoverishment of agriculture soils, the occidental population is consuming less magnesium than required [2,3]. Magnesium deficiency has been associated with cardiovascular pathologies [4,5], Diabetes Mellitus type I and II $[6,7]$, asthma [8], anxiety [9] and depression [10].

In human adult total corporal magnesium reached $20-24 \mathrm{~g}$ [3]. Almost $65 \%$ of it is found in bones, $27 \%$ in muscles, $7 \%$ in soft tissue and $1 \%$ in the extracellular fluids [11]. Magnesium in bones is the exchangeable pool that buffers systemic changes in magnesium concentration [12-14]. Thus, bone magnesium level indicates magnesium corporal status. Unfortunately, biopsy limits its routine use.

Magnesium in plasma corresponds to $0.3 \%$ of total corporal magnesium. In healthy humans plasma magnesium concentration ranged from $0.75-0.96 \mathrm{mmol} / \mathrm{L}$ [15]. While severe hypomagnesemia reflects low corporal content, normomagnesemia does not necessarily indicate normal corporal status [5]. Furthermore, the equilibrium between intracellular and plasma magnesium pools is achieved very slowly. Thus, whether magnesium assessed in plasma reflects its corporal status is, still, a matter of controversy [3,4,15-18].

The aim of this study was to identify a suitable sample for the assessment of magnesium corporal status in moderate deficiency using the simplest analytical technique.

\section{Materials and Methods}

\section{Animals and diets}

C57BL6 female mice 8 week-old were housed in individual cages at constant temperature $\left(22^{\circ} \mathrm{C}\right)$, with a $12: 12$ light-dark cycles and fed ad libitum with either normal $(121 \mathrm{mg} / 100 \mathrm{~g}$ food, D11112201) or low (39 mg/100 g food D14021701) magnesium diet (Research Diets Inc. USA). The former diet exceeds and the later ensures $78 \%$ of daily mice requirements [10].

When required, animals were anesthetized by an intraperitoneal injection of Ketamine $50 \mathrm{mg} / \mathrm{Kg}$ and Xylacine 5 $\mathrm{mg} / \mathrm{Kg}$, and sacrificed by cervical dislocation. All animal protocols were approved by the Committee of Care and Use of Experimental Animals of Facultad de Medicina Clinica Alemana Universidad del Desarrollo. 


\section{Procuration, processing and storage of samples}

Bone and muscle samples from femur and tibia were procured immediately after sacrifice, rinsed in physiological serum and dried for one hour at $90^{\circ} \mathrm{C}$. Blood samples were collected by intracardiac puncture with heparinized syringes and tubes. For platelets isolation, $500 \mu \mathrm{L}$ of whole blood was centrifuged at $200 \mathrm{~g}$ for 20 minutes at room temperature. The supernatant containing platelet rich plasma was further centrifuged at $1,600 \mathrm{~g}$ for 10 minutes and the pellet obtained was suspended in physiological serum. Platelets were counted using a flow cytometer (Dako, USA). For plasma isolation, whole blood was centrifugated at $1600 \mathrm{~g}$ for 10 minutes at room temperature.

All samples were stored at $-80^{\circ} \mathrm{C}$ until been analyzed.

\section{Measurement of magnesium content}

Bone and muscle samples were calcined for 8 hours. Magnesium was determined by atomic absorption spectroscopy in Atomic Absorption Spectrometer Spectra 55B Varian [17]. Platelets and plasma were thawed at room temperature, and the total magnesium in them was determined using a colorimetric kit (Mg color-AA. Wiener Lab, Argentina). Briefly, in alkaline solution, magnesium react with Xilydyl Blue forming a purple-red complex, being its intensity proportional to the magnesium concentration present in the sample [19]. The procedure was: $10 \mathrm{ul}$ of plasma was mixed with $1 \mathrm{ml}$ of reagent, after 5 minutes of incubation at room temperature the intensity of color was measured at $510 \mathrm{~nm}$ Briefly, [19]. Calcium interference was avoided by the addition of ethylene glycol tetraacetic acid to the reaction mixture [20].

\section{Statistical analysis}

Data are presented as mean \pm SEM. Group comparisons were performed by unpaired T-test. $p<0.05$ was considered statistically significant. The association between content of magnesium in bones and plasma was established by Pearson correlation. ROC analysis was done to identify the value of plasmatic magnesium concentration that allows to distinguish between normal and moderate deficient individuals (bone magnesium $\leq 15 \mathrm{mmol} / 100 \mathrm{~g}$ ) [21].

Graphics were generated with GraphPad Prism version 6 (GraphPad Software, La Jolla, CA, USA).

\section{Results}

As shown in Figure 1A, animals fed for 45 days with a low magnesium diet did not modify their body weight. Together, no adverse effect (loss of awareness, change in food and water intake, disease development) was observed.

Bone magnesium was significantly diminished in animals fed with low magnesium diet compared with animals fed with the regular diet $(14.6 \pm 0.5$ versus $16.7 \pm 0.2 \mathrm{mmol} / 100 \mathrm{~g}, \mathrm{p}<0.05)$ (Figure 1B). Since the content of magnesium in bones is the main indicator of its corporal status, these data support a moderate magnesium deficiency model. Compared with normal mice, moderate magnesium deficient animals present no differences of magnesium content in muscles or platelets (Figures 2A and 2B). Nevertheless its concentration in plasma replicates the differences observed in bones (Figure $\mathbf{2 C}$ ).

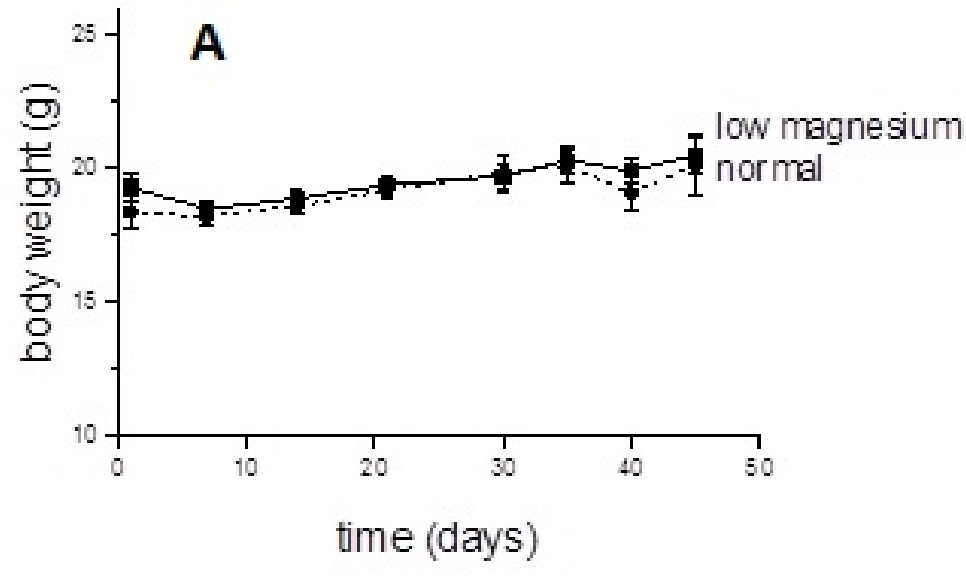

B

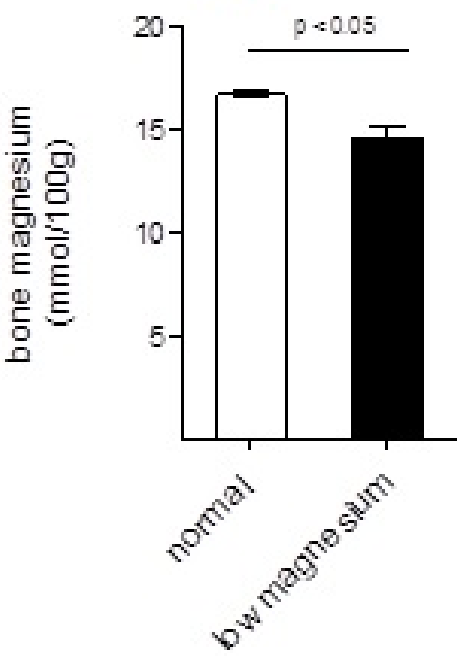

Figure 1 Animal model of moderate magnesium deficiency, A) The body weight of mice was determined along the study period (normal $n=32$, low magnesium diet $n=35$ ). B) Forty-five days after diet switch magnesium content was measured in bone samples by atomic absorption spectrophotometric (normal $n=3$, low magnesium diet $n=5$ ). 

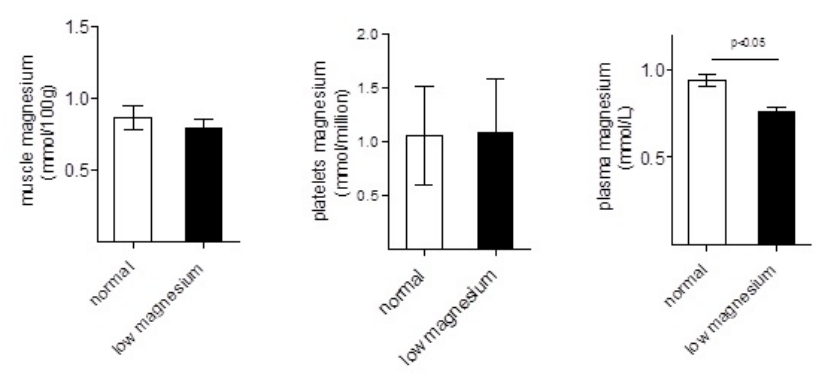

Figure 2 Plasma magnesium concentration reflects moderate magnesium deficiency. Magnesium content was measured in muscle (A), platelets (B) and plasma (C) obtained from normal and moderate magnesium deficient mice (normal $n=3$, low magnesium $n=8$ ).

Pearson correlation was performed with data obtained from 37 animals, with different sex, age and magnesium corporal status. The association obtained between magnesium concentration assessed in bone and plasma was 0.53 (Figure 3A). ROC curve analysis revealed an area under the curve of 0.78 (IC $0.60-0.95, p<0.05$ ), 83\% specificity and $75 \%$ sensibility for plasma magnesium cut off of $0.84 \mathrm{mmol} / \mathrm{L}$ (Figure 3B).
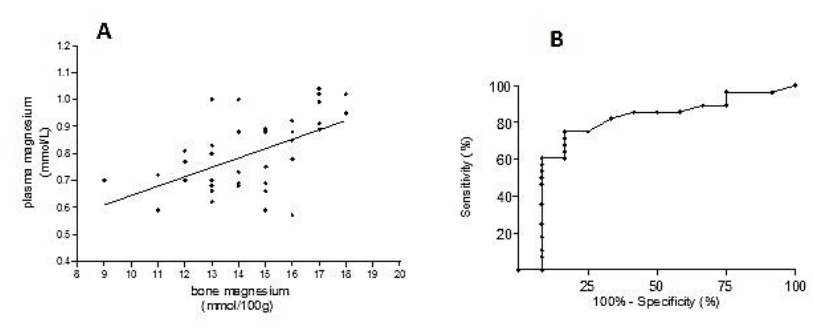

Figure 3 Poor accuracy of colorimetric magnesium assessment in plasma samples. A) Association between bone and plasma magnesium content was determined using Pearson correlation, $r=0.53(n=37)$. B) Specificity and sensitivity of plasma magnesium assessment was determined using ROC curve. AUC=0.78 (IC 0.60-0.95, $\mathrm{p}<0.05)$. The arrow indicates the point of maximum specificity and sensitivity $(0.84 \mathrm{mmol} / \mathrm{L})$.

\section{Discussion}

Here we presented an animal model of moderated magnesium deficiency generated after feeding mice for 45 days with a diet that supplies $78 \%$ of their daily requirement (39 versus $50 \mathrm{mg} / 100 \mathrm{~g}$ of food) [9]. Moderate magnesium deficiency is detectable only in bone and plasma samples.

Our mice model mimics better the magnesium deficiency in humans than rat model previously described because rats were fed with a diet that supply only $10 \%$ of their daily requirement and developed severe hypomagnesemia $(0.6$ $\mathrm{mmol} / \mathrm{L}$ versus $1.2 \mathrm{mmol} / \mathrm{L}$ ) in only 14 days [22].
In moderate magnesium deficient mice we did not observed a statistically significant difference in muscle magnesium content compared to normal mice. It is known that the equilibrium of magnesium in muscle takes long time [13]. Therefore if deficiency is prolonged this would be reflected in muscle tissue.

Our results regarding platelets content of magnesium showed great intragroup variability, both in normal and moderate deficient individuals. This may be due to platelet activation during the isolation process [23]. Thus, though platelets have been suggested as a good candidate to assess intracellular magnesium content the variability caused by handling prevents its use in the assessment of magnesium corporal status.

The modest correlation found between bone and plasma magnesium concentration is explain because: i) most samples became from individuals with moderate magnesium deficiency. Hence, their plasma magnesium concentration placed in the center of the curve, ii) intra-assay precision for colorimetric method used was for high values CV $4.3 \%$ and for low values CV $20 \%$. These numbers are in agreement with data previously reported (1\%-12\%) [24]. The later also limits the sensitivity (75\%) and specificity (83\%) of the assay when using plasma samples. Thus, our data supports the fact that the validity to assess magnesium corporal status in individuals with moderate magnesium deficiency depends on the analytical technique rather than the sample.

In conclusion, the plasma is a proper sample to study magnesium corporal status when deficiency is moderate. Unfortunately, the high variability of the colorimetric technique limited assay accuracy. It would be desirable to have a simple technique with a high performance.

\section{Acknowledgements}

The authors are grateful to Javiera Bahamonde for English editing of the manuscript

This work was supported by Grant Number 23400109, Dirección de Investigación, UDD

\section{References}

1. De Baaij JH, Hoenderop JG, Bindels RJ (2012) Regulation of magnesium balance: lessons learned from human genetic disease. Clin Kidney J 5: 15-24.

2. Rosanoff A, Weaver C, Rude R (2012) Suboptimal magnesium status in the United States: are the health consequences underestimated? Nutrition Reviews 70: 153-164.

3. De Baaij JH, Hoenderop JG, Bindels RJ (2015) Magnesium in man: implications for health and disease. American Physiological Society 95: 1-46

4. Ganga H, Noyes A, White CM, Kluge J (2013) Magnesium adjunctive therapy in atrial arrhythmias. Pace 36: 1308-1318.

5. Shechter M (2010) Magnesium and cardiovascular system. Magnesium research 23: 60-72. 
6. Simsek E, Karabay M, Kocabay K (2005) Assessment of magnesium status in newly diagnosed diabetic children: measurement of erythrocyte magnesium level and magnesium tolerance testing. The Turkish Journal of Pedriatrics 47: 132-137.

7. Takaya J, Higashino H, Kobayashi Y (2004) Intracellular magnesium and insulin resistance. Magnesium Research 17: 126-136.

8. Kazaks A, Uriu-Adams J, Albertson T, Shenoy S, Stern J (2010) Effect of oral magnesium supplementation on measures of airway resistance and subjective assessment of asthma control and quality of life in men and women with mild to moderate asthma: a randomized placebo controlled trial. J Asthma 47: 83-92.

9. Sartori S, Whittle N, Hetzenauer A, Singewald N (2012) Magnesium deficiency induces anxiety and HPA axis dysregulation: modulation by therapeutic drug treatment. Neuropharmacology 62: 304-312.

10. Whittle N, Li L, Chen W, Yang J, Sartori S, et al. (2011) Changes in brain protein expression are linked to magnesium restrictioninduced depression-like behaviour. Amino Acids 40: 1231-1248.

11. Aranda P, Planells E, Llopis J (2000) Magnesio. Ars Pharmaceutica 41: 91-100.

12. Alfrey A, Miller N, Butkus D (1974) Evolution of corporal magnesium stores. The journal of Laboratory and Clinical Medicine 84: 153-162.

13. Jahnnen-Dechent W, Ketteler M (2012) Magnesium basics. Clin Kidney J 5: 13-14.

14. Nielsen F (2009) Dietary fatty acid composition alters magnesium metabolism, distribution, and marginal deficiency response in rats. Magnesium Research 22: 280-288.
15. Elin RJ (2010) Assessment of magnesium status for diagnosis and therapy. Magnesium Research 23:194-198.

16. Huijgen $H$, Van Ingen $H$, Sandres R, Gaffar F, Oosting J, et al. (1997) Precision of magnesium determination in mononuclear blood cells and erythrocytes. Clinical Biochemistry 30: 203-208.

17. Ayuk J, Gittoes N (2011) How should hypomagnesemia be investigated and treated? Clinical Endocrinology 75: 743-746.

18. Arnaud MJ (2008) Update on the assessment of magnesium status. Br J Nutr 99: S24-S36.

19. Chromy V, Svodova V, Stepanova I (1973) Spectrophotometric determination of magnesium in biological fluids with Xilydyl Blue II. Biochemical Medicine 7: 208-217.

20. Mann CK, Yoe JH (1956) Spectrophotometric Determination of Magnesium with Sodium 1-Azo-2- hydroxy-3-(2,4dimethylcarboxinilido)-naphthalene-1-(2-hydroxybenzene-5sulfonate) Analytical Chemistry 28: 202-205.

21. Cerda J, Cifuentes L (2012) Using ROC curves in clinical investigation. Theoretical and practical issues. Revista Chilena de infectología 29: 138-141.

22. Sabbagh F, Lecerf F, Hulin A, Bac P, German-Fattal M (2008) Effect of hypomagnesemia on allogenic activation in mice. Transplant Immunology 20: 83-87.

23. Fox Ch, Timm E, Smith S, Touyz R, Bush E, et al. (2007) A method for measuring intracellular free magnesium concentration in platelets using flow cytometry. Magnesium Research 20: 200-207.

24. Izquierdo S, Boudet A, Otero S, María M, González J, et al. (2008) Estimation of precision and inaccuracy for serum magnesium determination on the basis of interlaboratory comparison data. Accreditation ISO 15189. Magnesium Research 21: 51-57. 